\title{
Fermentation of hemp seed proteins leads to formation of peptides that share sequence similarity with human vitamin D-binding protein
}

\author{
Marco Ruggiero* and Stefania Pacini \\ Silver Spring Sagl, Switzerland
}

\begin{abstract}
In this article, we describe how fermentation of hemp seed proteins leads to formation of peptides that share sequence similarities with human vitamin D-binding protein. We compared the amino acid sequence of edestin, the major hexameric globular protein from hemp protein isolates, with that of human vitamin D-binding protein, and we found significant functional similarities. Among the different peptides formed during the process of fermentation, we identified the peptide VLANAFQ of edestin as a promising candidate showing a high degree of functional similarity as well a common pattern of hydrophobicity with the TPTELAKLVNKRSE peptide that is the active site of human vitamin D-binding protein as far as it immune-stimulating, anti-proliferative and anti-migration properties are concerned.
\end{abstract}

\section{Introduction}

Vitamin D-binding protein-derived Macrophage Activating Factor (DBP-MAF or Gc-protein-derived MAF) and its conceptual derivative based on microbial chondroitin sulfate, proved effective in a number of conditions characterized by immune system and mitochondrial dysfunction thanks to their effects on the pathogenetic alterations that are common to chronic conditions [1-9]. We and others demonstrated that DBP-MAF interacts in vitro also with cells other than macrophages [10-12], thus lending credit to the hypothesis that the biological effects described in previous studies [1-9] may be ascribed to a combination of effects encompassing stimulation of the immune system through the macrophage-immune system pathway, as originally postulated, as well as direct effects on target cells. Here we demonstrate that fermentation of hemp seed proteins utilizing an ad hoc designed microbial formula 1 eads to formation of peptides endowed with biological activity similar to that of DBP-MAF.

\section{Materials and methods}

\section{Fermentation of hemp seed proteins}

The process of fermentation of hemp seed protein extract was performed in Switzerland using the following materials:

Mineral water (France).

Hemp seed protein extract (Switzerland and Europe).

Fresh lemon juice, not from concentrate (Switzerland).

White sugar (Switzerland).

Apple cider vinegar (Switzerland).

Proprietary probiotic formula (Switzerland and Europe) containing Lactobacillus salivarius, Lactobacillus acidophilus, Lactobacillus paracasei, Lactobacillus rhamnosus, Lactococcus lactis, Bifidobacterium infantis, Bifidobacterium bifidum, Bifidobacterium lactis, Bifidobacterium longum, and proprietary cultured kefir grains whose peculiar microflora was recently described $[13,14]$.

Hemp seed protein extract was dissolved in mineral water and heat-treated with the goal of inducing mild unfolding of the native structure of edestin, an hexameric globular protein, so to expose sites where proteolysis by microbial proteases could occur with the consequent formation of bioactive peptides. Exhaustive preliminary experiments were performed to identify the ideal conditions to induce mild unfolding of the native structure without significant protein denaturation. Preliminary experiments were also performed to identify the ideal times and temperatures for efficient fermentation as well as the ratio of the different components. The mineral water was chosen for its peculiar mineral content; preliminary experiments performed using mineral-depleted water indicated that an array of natural minerals was necessary for optimal microbial fermentation. Using mineral water with defined mineral content, the absolute number of live microbes dramatically increased during the fermentation period. The fermented product was then freeze-dried and analyzed for biological activity on human cell cultures.

Study of biological activity on human cell cultures; clonogenic assay

The fermented product was assayed for biological activity using soft-agar clonogenic assay performed by an independent laboratory (ProQinase GmbH, Freiburg, Germany) as described below. $500 \mathrm{mg}$ of

${ }^{\star}$ Correspondence to: Marco Ruggiero, Silver Spring Sagl, Via Raimondo Rossi 24, Mendrisio 6850, Switzerland, Tel: +41 79230 9283, E-mail: marco. drruggiero@gmail.com

Key words: hemp, human vitamin D-binding protein, peptides, probiotics; edestin

Received: January 07, 2020; Accepted: January 20, 2020; Published: January 23, 2020 
the freeze-dried fermented compound were weighed, taken into solution in $6.5 \mathrm{~mL}$ of DMEM medium by 30 min heating at $39^{\circ} \mathrm{C}$ under stirring to reach a $16 \mathrm{x}$ fold concentrated stock solution. Insoluble components were removed first by centrifugation, and then by filtration through a $0.22 \mu \mathrm{m}$ filter. Centrifugation and filtration eliminated all microbial cells and aggregates of insoluble proteins and other macro-molecules. Absence of microbial cells was indirectly confirmed by absence of any contamination of the cell cultures during the 8 day incubation in soft agar. It may be presumed that small peptides were most likely to pass through the filter at variance with hydrophobic globular proteins such as edestin, the major component of hemp seed protein isolates, that have the tendency to clump together. The resulting solution was diluted in DMEM and immediately $10 \mu \mathrm{L}$ was added to each well containing human colon cells bearing mutation of the KRAS gene (HCT116 cell line, 2,500 cells/well). No treatment (solvent) and Staurosporine $(10 \mu \mathrm{M})$ served as high control (100\% viability) and low control $(0 \%$ viability), respectively. Treatment of cells started one day after seeding. For the HCT116 cell line, a 96 well suspension cell culture plate was prepared. $100 \mu \mathrm{L}$ of the soft agar bottom layer $(0.6 \%$ final concentration in complete medium) was poured and left to solidify. $50 \mu \mathrm{L}$ of the soft agar top layer ( $0.4 \%$ final concentration) containing the corresponding cells and cell number were then added on top, solidified and incubated overnight at $37^{\circ} \mathrm{C}$, in $10 \% \mathrm{CO}_{2}$. The following day, the freeze-dried fermented compound and the controls were added into the inner wells of the plate. Subsequently, the assay was incubated in a cell culture incubator for 8 days. Finally, the assay was developed using Alamar Blue and, upon $3 \mathrm{~h}$ of incubation at $37^{\circ} \mathrm{C}$, fluorescence intensity was determined (excitation: $560 \mathrm{~nm}$; emission: $590 \mathrm{~nm}$ ). As low control, cells were treated with Staurosporine $(10 \mu \mathrm{M})$. As high control, cells were treated with solvent.

\section{Results and discussion}

The protein/peptide content from the fermented hemp seed protein extract added to each well containing 2,500 cells was calculated as $0.6 \mu \mathrm{g} / \mathrm{well}$, an amount that is of the same order of magnitude as that used by Gregory et al. to assess the effects of DBP-MAF on transformed prostate cell proliferation and migration [10]. The fermented hemp seed protein extract caused inhibition of HCT116 cell proliferation that was statistically significant $(\mathrm{p}<0.05)$. We attribute this effect to formation of bioactive peptides from edestin. Edestin is an hexameric globular protein that bears striking functional resemblance to the human vitamin D-binding protein that is the precursor of DBP-MAF (Fig. 1). We postulate that proteases secreted by the microbes of the probiotic formulation, together with the increase of acidity that is characteristic of fermentation, led to formation of peptides functionally very similar to DBP-MAF and, in particular, to the peptide TPTELAKLVNKRSE that was identified by Gregory et al. as the active site of DBP-MAF [10]. The process through which fermentation would lead to formation of a bioactive peptide from edestin is identical, in principle, to the process leading to formation of bioactive peptides from hydrolysis of caseins during fermentation of milk by kefir grains [15]. Among the peptides with potential biological activity deriving from the proprietary edestin fermentation process here described, we identified the peptide VLANAFQ as the most promising candidate. This peptide shows a high degree of functional similarity as well a common pattern of hydrophobicity with the TPTELAKLVNKRSE peptide described by Gregory et al. [10]. It is worth noticing that formation of vegetal bioactive peptides from fermentation of hemp seed proteins is reminiscent of the formation of DBP-MAF from fermented bovine colostrum [16]. Edestin, as a major component of hemp protein isolates, is known for

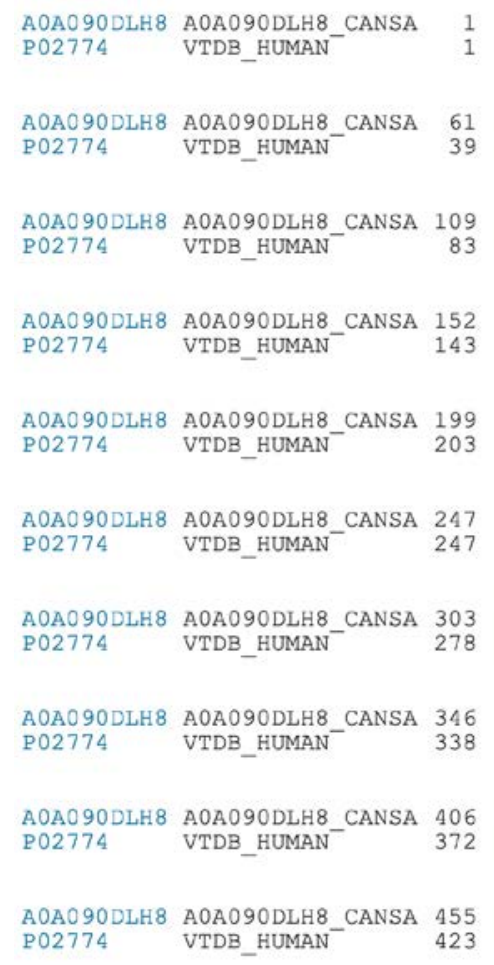

Figure 1. Sequence alignment between edestin and vitamin D-binding protein

The sequences of edestin 1 (A0A090DLH8) and vitamin D-binding protein (also known as Gc-protein; P02774) were obtained and aligned using the Align tool of Uniprot (uniprot.org). The light indigo color indicates hydrophobicity. The conventional consensus symbols are: "*" indicating that the residues are identical in all sequences in the alignment. ":" indicating that conserved substitutions have been observed. "." indicating that semi-conserved substitutions are observed, that is, amino acids having similar features.

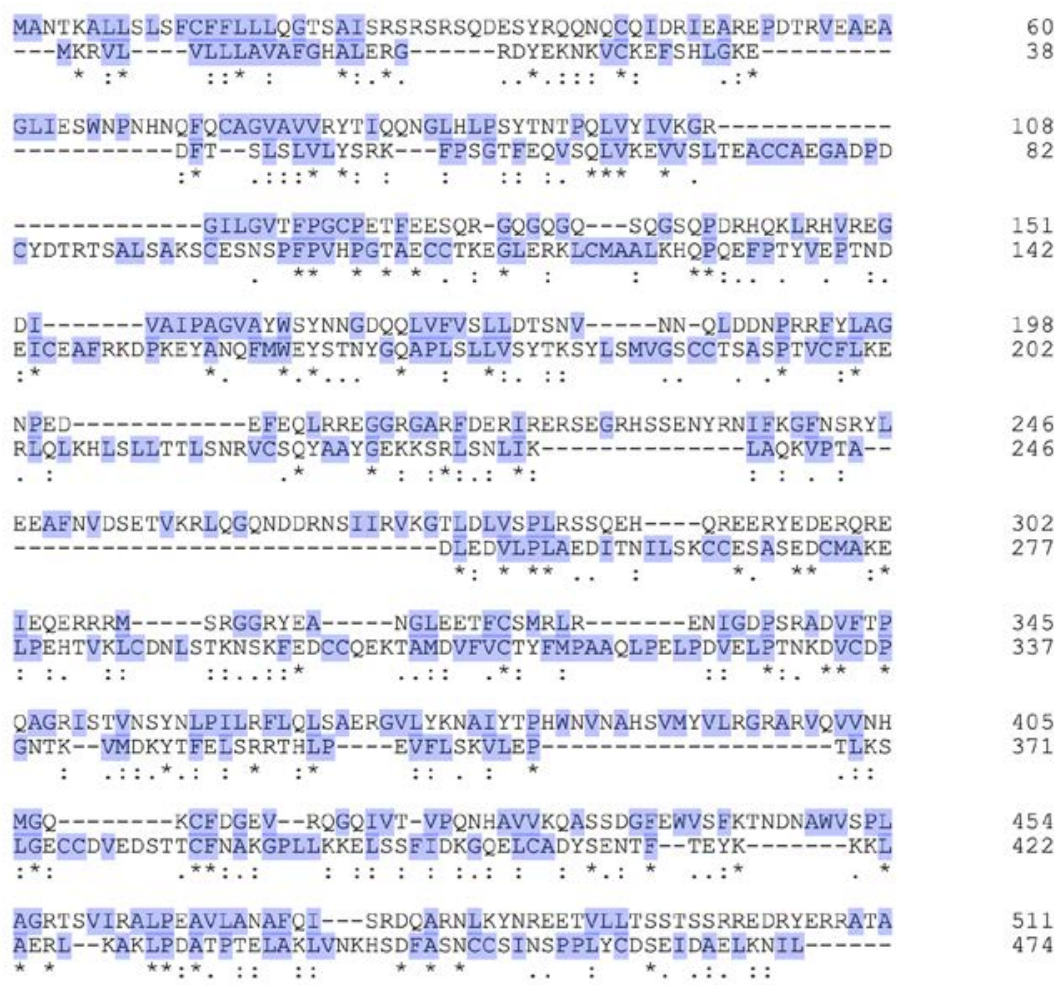


its excellent nutritional properties and it was recently hypothesized that products of its hydrolysis may have bioactive properties [17]. To our knowledge this is the first demonstration that fermentation of edestin leads to formation of peptides that show biological activity in human cell cultures (Figure 1).

\section{Authorship and contributorship}

Marco Ruggiero and Stefania Pacini developed the concepts described in this paper and contributed equally to this manuscript.

\section{Competing interests}

Marco Ruggiero is the founder and CEO of Silver Spring, a Swiss company dedicated to research, development, and production of supplements and probiotics. Stefania Pacini is a consultant for Silver Spring Sagl. Marco Ruggiero and Stefania Pacini have invented a number of products and consult for several companies. The results presented in this paper were obtained by an independent laboratory as specified in the Materials and Methods.

\section{Advisory}

No information in this paper is presented by the authors as medical advice. Caregivers, researchers and interested parties should research all information given. Beginning any significant biomedical or other interventions that may impact physiology or making changes to an established regimen should be discussed with the patient's physician in advance. Standard of care for each pathology must be followed as well as rules and regulations established by Health Authorities of each Country.

\section{References}

1. Thyer L, Ward E, Smith R, Branca JJ, Morucci G, et al. (2013) GC protein-derived macrophage-activating factor decreases $\alpha$-N-acetylgalactosaminidase levels in advanced cancer patients. Oncoimmunology 2: e25769. [Crossref]

2. Ruggiero M, Ward E, Smith R, Branca JJ, Noakes D, et al. (2014) Oleic Acid, deglycosylated vitamin D-binding protein, nitric oxide: a molecular triad made lethal to cancer. Anticancer Res 34: 3569-78. [Crossref]

3. Saburi E, Saburi A, Ghanei M (2017) Promising role for Gc-MAF in cancer immunotherapy: from bench to bedside. Caspian J Intern Med 8: 228-238. [Crossref]
4. Ruggiero M, Pacini S (2018) Rationale for the design of a novel tool for immunotherapy based on an emulsion of glycosaminoglycan. Integr Cancer Sci Therap 5: 285.

5. Antonucci N, Pacini S, Ruggiero M (2019) Use of an extremely biodiverse probiotic and a supplement based on microbial chondroitin sulfate is associated with a significant decrease of serum free kappa light chains as well as a trend toward normalization of kappa/lambda ratio and of plasma cell bone marrow infiltration in a case of multiple myeloma. Am J Immunol 15: 5-9.

6. Bradstreet JJ, Vogelaar E, Thyer L (2012) Initial Observations of elevated Alpha-nAcetylgalactosaminidase Activity Associated with Autism and Observed Reductions from GC Protein-Macrophage Activating Factor Injections. Autism Insights 4: 31-38.

7. Antonucci NS, Ruggiero PM (2019) Clinical Experience of Integrative Autism treatment with a Novel type of Immunotherapy. Madridge J Vaccines 3: 71-76.

8. Ruggiero M, Pacini S (2018) From neurology to oncology: what have in common autism and cancer? the role of oncogenes, immune system and microbiota. J Neurol Stroke 8: 166-172.

9. Pacini S, Ruggiero M (2019) Color Doppler evaluation of isovolumetric relaxation time and of signals arising from axons of the median nerve as a means to evaluate mitochondrial functionality in the context of immunotherapy of cancer and chronic conditions associated with mitochondrial dysfunction. Am J Immunol 15: 22-32.

10. Gregory KJ, Zhao B, Bielenberg DR, Dridi S, Wu J, et al. (2010) Vitamin D binding protein-macrophage activating factor directly inhibits proliferation, migration, and uPAR expression of prostate cancer cells. PLoS One 5: e13428. [Crossref]

11. Pacini S, Punzi T, Morucci G, Gulisano M, Ruggiero M (2012) Effects of vitamin D-binding protein-derived macrophage-activating factor on human breast cancer cells. Anticancer Res 32: 45-52. [Crossref]

12. Morucci G, Branca JJ, Gulisano M, Ruggiero M, Paternostro F, et al. (2015) Gcprotein-derived macrophage activating factor counteracts the neuronal damage induced by oxaliplatin. Anticancer Drugs 26: 197-209. [Crossref]

13. Pacini S, Ruggiero M (2019) Phage composition of a fermented milk and colostrum product assessed by microbiome array; putative role of open reading frames.

14. Pacini S, Ruggiero M (2019) Natural Plasmids in a Swiss Fermented Milk and Colostrum Product assessed by Microbiome Array. Madridge J Immunol 3: 100-108.

15. Ebner J, Așçı Arslan A, Fedorova M, Hoffmann R, Küçükçetin A, et al. (2015) Peptide profiling of bovine kefir reveals 236 unique peptides released from caseins during its production by starter culture or kefir grains. J Proteomics 117: 41-57. [Crossref]

16. Pacini S, Punzi T, Morucci G, Ruggiero M (2011) Macrophages of the mucosaassociated lymphoid tissue (MALT) as key elements of the immune response to vitamin $\mathrm{d}$ binding protein-macrophage activating factor. It J Anat Embryol 116: 136.

17. Mamone G, Picariello G, Ramondo A, Nicolai MA, Ferranti P (2019) Production, digestibility and allergenicity of hemp (Cannabis sativa L.) protein isolates. Food Res Int 115: 562-571. [Crossref]

Copyright: (C2020 Ruggiero M. This is an open-access article distributed under the terms of the Creative Commons Attribution License, which permits unrestricted use, distribution, and reproduction in any medium, provided the original author and source are credited. 